\title{
THE ACID-BASE EQUILIBRIUM IN PATHOLOGICAL CONDITIONS
}

\section{ALKALOSIS OBSERVED IN HYPERTENSIVE STATES ${ }^{1}$}

BY EDWARD MUNTWYLER AND CHARLES T. WAY

with The Technical Assistance of DOROTHY BINNS

(From the Department of Biochemistry, School of Medicine, Western Reserve University, Cleveland)

(Received for publication April 29, 1931)

Nephritis with nitrogen retention has generally been considered to be associated with a progressive acidosis. Whitney (1) and Chace and Myers (2) were among the first to point this out. The latter - workers observed that all fatal cases of chronic nephritis with marked nitrogen retention showed a severe acidosis, sufficient in many instances to be the actual cause of death. Since acidosis is a term applied to conditions in which the bicarbonate concentration of the blood is low, it may arise from several causes: a reduction of the total base concentration or an increase of the acid ions. An influx of acid into the blood may occur from an abnormal formation as in diabetes mellitus or from a decreased elimination as in chronic nephritis. Marriott and Howland (3) demonstrated an increase in the phosphate of the serum in nephritis with a lowered $\mathrm{CO}_{2}$ capacity of the plasma and decrease in plasma pH. Greenwald (4), Denis and Minot (5), Salvesen and Linder (6), and Schmitz, Rohdenburg and Myers (7)

1 This investigation was aided by a grant from the Josiah Macy, Jr., Foundation.

A preliminary report of this work was presented before the American Society for Experimental Pathology, Chicago, March 1930. J. Biol. Chem., 1930, lxxxvii, iv.

Most of the cases in this study were on the service of one of us (C. T. W.) in the Medical Wards of St. Luke's Hospital; the rest were in the Medical Wards of the City Hospital. We are indebted to Drs. R. W. Scott, W. F. Burger and H. A. Ruprecht for the privilege of studying the cases at City Hospital. 
have also shown retention of acid phosphate in nephritis. De Wesselow (8) pointed out that on the average the retentions of phosphates and urea run a parallel course. That phosphate may not be the only acid constituent to be retained was pointed out by Denis and Hobson (9), Loeb and Benedict (10), and Wakefield (11), who showed that in nephritis with nitrogen retention the $\mathrm{SO}_{4}$ ion is retained in the blood and roughly parallels the nitrogen retention.

Salvesen (12) studied the changes of the individual cations and anions along with the $\mathrm{pH}$ and $\mathrm{CO}_{2}$ tension in the blood of 37 cases having renal disorder. It was found that an acidosis is very frequent, and if acute nephritis is excluded the condition for acidosis is kidney insufficiency. In two of the cases observed by Salvesen the acidosis was attributable to an increased chloride. It was concluded that the most important factor causing acidosis is an accumulation of organic acid in the blood and this factor is aided by a more or less pronounced loss of base. Phosphate retention was considered of no importance.

Recently Peters, Wakeman, Eisenman and Lee (13) have also con-" sidered the factors causing the acidosis of nephritis by making a total acid-base equilibrium study of the plasma. The most striking fact observed was the frequency of reduction of the bicarbonate concentration. One of the electrolyte disturbances most frequently encountered was a deficiency of the total electrolyte (base) concentration of the serum and this was considered instrumental in the production of acidosis in a rather large proportion of cases. Phosphate increases were found relatively insignificant factors in causing acidosis. It was also concluded that sulfate and organic acids are less important than had been supposed. Chloride as well as bicarbonate was diminished in most cases with deficient base, and a reduction of $\mathrm{Cl}$ and base was usually encountered when vomiting was a serious symptom or when the patients had received limited amounts of salt and excreted large amounts of fluid. It was pointed out that one rather surprising fact seems to have been accepted without comment by previous observers, "that bicarbonate is never found elevated in a condition in which vomiting is such a prominent symptom."

Before the appearance of the above report, the possibility of finding an increased bicarbonate in connection with cases showing vomiting had attracted us to study cases of hypertension in which vomiting. 
was a prominent symptom since it was early pointed out by Kast, Myers and Schmitz (14) that vomiting may lead to alkalosis. A study of the acid-base equilibrium has been made in twelve cases, which were characterized by a persistent high blood pressure with only moderate or no nitrogen retention. The first two cases reported were the only ones in which there was considerable vomiting.

\section{METHODS EMPLOYED}

The blood, usually 25 or $30 \mathrm{cc}$., was withdrawn from an arm vein under oil and without stasis. All samples were taken before breakfast. The blood was immediately transferred under oil to a special centrifuge tube and tightly stoppered. After removing enough blood under oil for oxygen capacity determinations, the sample was centrifuged and the plasma separated as quickly as possible and placed under oil in a special tube as described elsewhere (15). The $\mathrm{CO}_{2}$ content and $\mathrm{pH}$ estimations were then made immediately.

To prevent clotting, heparin was employed $(1 \mathrm{mgm}$. heparin for 5 cc. of blood). This was carefully weighed and placed in the centrifuge tube. A small drop of distilled water was added to the heparin in order to make a paste. This made possible the free mixing of the blood with the heparin when placed under oil.

The carbon dioxide content was determined by the method of Van Slyke and Neill (16). For the estimation of chlorides the method of Van Slyke (17) was employed. With the introduction of the modification by Wilson and Ball (18) the latter procedure was employed. The $\mathrm{pH}$ was determined colorimetrically as described by Myers and Muntwyler (15). The procedure was the same except in the adjusting of the saline indicator solution. Instead of employing 1 per cent $\mathrm{NaOH}$ to adjust the saline solution to $\mathrm{pH} 7.55, \mathrm{CO}_{2}$ free air was drawn through the solution until the $\mathrm{pH}$ was 7.4 to 7.5. For total base, the method of Stadie and Ross (19) was employed. The phosphate of the plasma was not determined in all cases. For this reason the total base figures were not corrected for the loss by combination with phosphate. Since, however, the phosphate was found normal when determined, only a small error is introduced by this omission. For the determination of total protein $0.5 \mathrm{cc}$. of plasma was subjected to a Kjeldahl procedure. From the total nitrogen $30 \mathrm{mgm}$. per $100 \mathrm{cc}$. was sub- 
tracted. This is to correct for nonprotein nitrogen, as the latter was not determined in all cases.

\section{CALCULATIONS}

The value for grams total protein per $100 \mathrm{cc}$. was converted into milliequivalents of base combined with protein by the formula of Van Slyke, Hastings, Hiller and Sendroy in the form used by Peters, et al. (13),

$$
\mathrm{BP}=1.072 \mathrm{P}(\mathrm{pH}-5.04),
$$

in which an albumin : globulin ratio of 1.8 was assumed. $\mathrm{BP}$ and $\mathrm{P}$ represent respectively the milliequivalents of base combined with protein per liter of serum and grams of protein per $100 \mathrm{cc}$.

The milliequivalents of base combined as $\mathrm{BHCO}_{3}$ were obtained from the $\mathrm{pH}$ and total $\mathrm{CO}_{2}$ by the following equation:

$$
\text { m.Eq. } \mathrm{BHCO}_{3}=\mathrm{CO}_{2}-\frac{\mathrm{CO}_{2}}{\left(10^{\mathrm{pH}-6.10}+1\right)},
$$

in which $\mathrm{CO}_{2}$ is the $\mathrm{mM}$. concentration of total $\mathrm{CO}_{2}$.

The total measured acid (T.A.) in this discussion is taken as

$$
\text { T.A. }=\mathrm{BHCO}_{3}+\mathrm{BCl}+\mathrm{BP} \text {, }
$$

where $\mathrm{BHCO}_{3}, \mathrm{BCl}$ and $\mathrm{BP}$ represent milliequivalents of base combined with $\mathrm{HCO}_{3}, \mathrm{Cl}$ and $\mathrm{P}$ respectively. The difference between the total base (T.B.) determined and the total measured acid is termed the undetermined acid and represents the amount of base equivalent to the phosphate, sulfate and salts of organic acids.

\section{RESULTS}

The results of the plasma analyses of twelve cases with persistent hypertension are collected in Table I. Whenever possible, the cases were observed over considerable periods of time, the blood samples being taken either every week or every other week. In this way successive changes to termination were followed.

If one assumes a plasma bicarbonate concentration of $31 \mathrm{~m}$. Eq. as the upper limit of normal, a condition of alkalosis existed in six cases at some period in the observation (Cases 1, 2, 3, 4, 5 and 7). The highest plasma bicarbonate was observed with Case 1, where the 
concentration varied between 34 and $37 \mathrm{~m}$.Eq. over a period of twentytwo days just preceding death, and during which time the patient presented an uncontrollable vomiting. The only other case to show vomiting was Case 2 and here the plasma bicarbonate reached a maximum value of $35 \mathrm{~m}$.Eq. The lowest bicarbonate concentration encountered was $18.1 \mathrm{~m}$.Eq. This was found in the terminal blood of Case 3. It should be pointed out, however, that this case had previously shown a maximum bicarbonate concentration of $32 \mathrm{~m}$.Eq. The great majority of the plasma bicarbonate concentrations were above $27 \mathrm{~m} . \mathrm{Eq}$.

The colorimetric $\mathrm{pH}$ of the plasma was found elevated in a greater number of cases than was the bicarbonate. $\mathrm{A} \mathrm{pH}$ above 7.48 was observed in all but one case, the maximum of 7.59 being observed with Case 4. The lowest $\mathrm{pH}$ value, 7.28, was obtained in the terminal blood of Case 3.

Considerable variation was encountered in the total base and chloride concentrations. Cases 1 and 2, which were accompanied by vomiting, had the lowest chloride concentrations observed, namely 83 and $85 \mathrm{~m}$. Eq. respectively. The highest chloride concentration observed was $107 \mathrm{~m}$.Eq. (Case 11). With the exception of 8 and 9, all the cases had chloride concentrations below $100 \mathrm{~m} . \mathrm{Eq}$. at some period during observation. In the individual cases observed over considerable periods of time the chloride concentration fluctuated widely. Cases 1 and 2 were accompanied with chloride decreases of 13 and $17 \mathrm{~m}$. Eq. respectively. This was undoubtedly augmented by the loss of chloride with vomiting. This decrease of chloride was accompanied by a decrease of total base and at the same time an increase in the bicarbonate concentration. The increase in bicarbonate was, however, not as great as the decrease in chloride with the consequence that the total measured acid concentration was decreased. Cases 3 and 5 had chloride changes of 11 and $13 \mathrm{~m}$.Eq. respectively. The highest bicarbonate concentration of Case 3 was present with the lowest chloride concentration. This was also the observation with Case 5. The total base appeared in most instances to change in the same direction as the chloride. The total base concentration varied from a high value of $176 \mathrm{~m}$.Eq. in Case 7 to a low value of 137 m.Eq. in Case 1. The total measured acid concentration was more uniform than the total base, varying between 152 and $132 \mathrm{~m}$.Eq. 


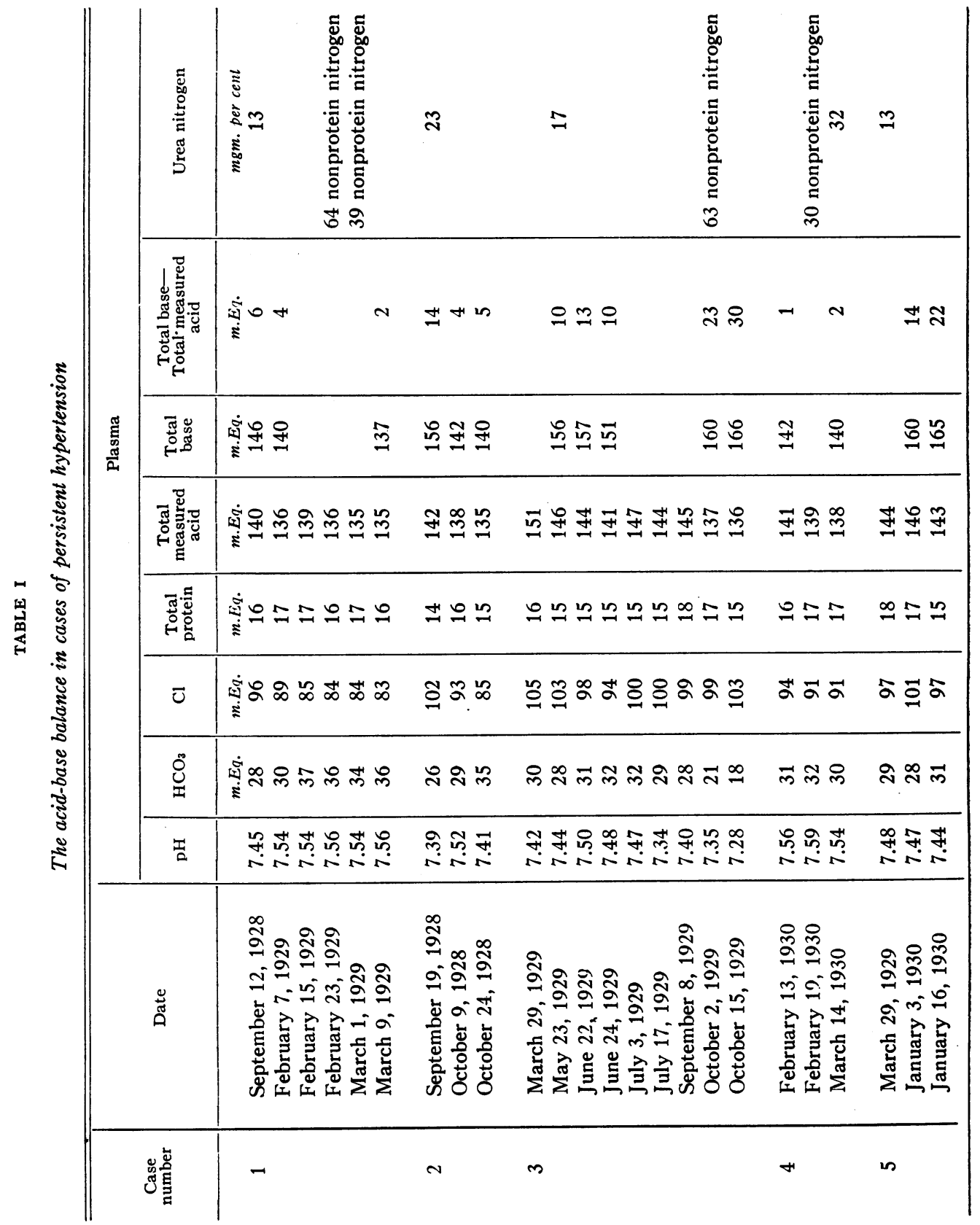


E. MUNTWYLER, C. T. WAY AND D. BINNS

495

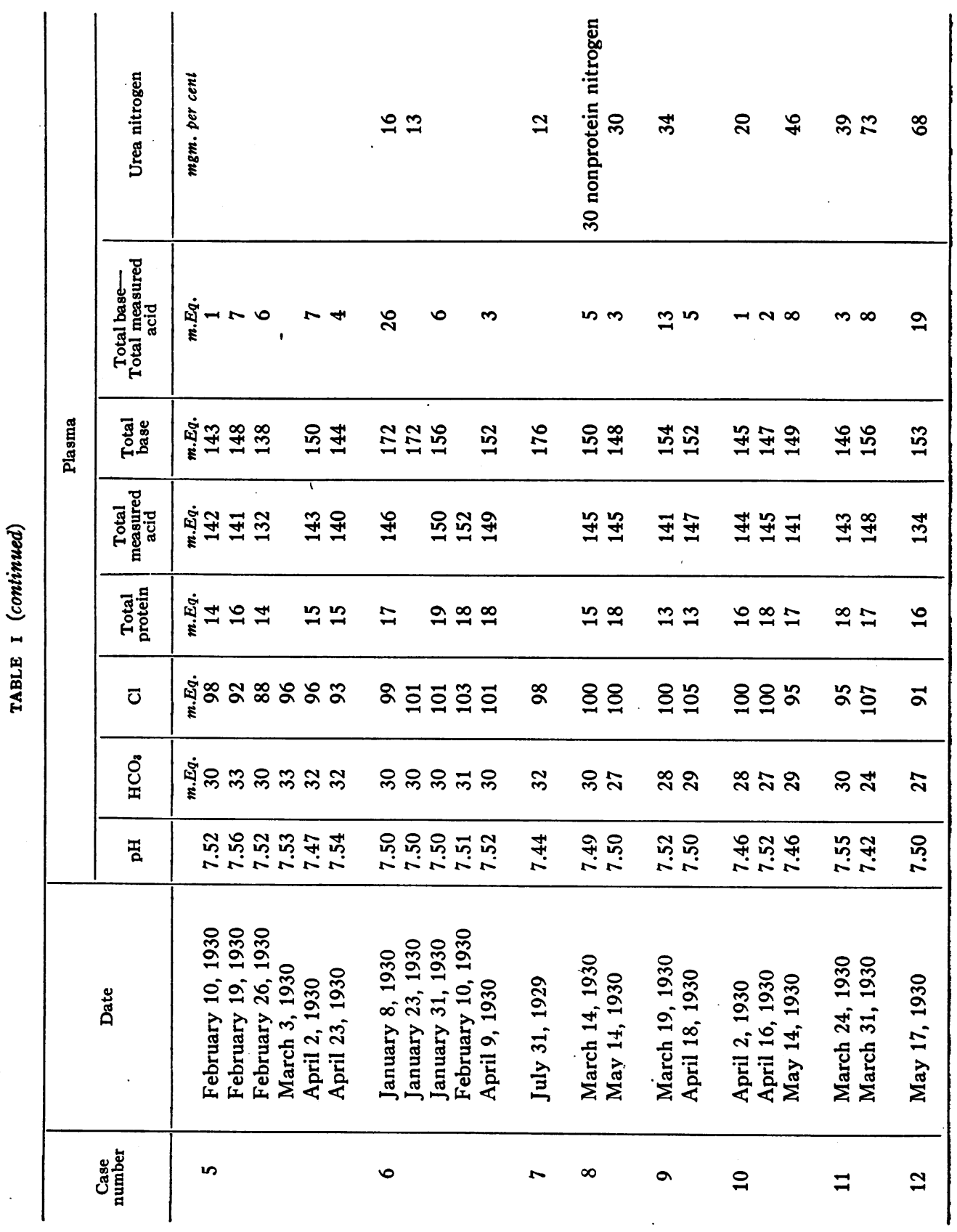




\section{DISCUSSION OF RESULTS}

At the outset of this study, interest was attracted to the influence of vomiting on the acid-base equilibrium of the plasma. It has been shown by a number of workers in pyloric obstruction, and by others (20) in cases of periodic vomiting from other causes, that there is an alkalosis as a result of the loss of acid from the body in the form of $\mathrm{HCl}$. The question of a loss of chloride in the vomitus was considered by Peters, Wakeman and Lee (21) in connection with the reductions of chloride and base observed in nephritis. They found that the vomitus of uremic patients, although not a negligible source of chloride loss, is usually not an important one. The chloride concentration in the vomitus often exceeded that in the urine, though the total volume of the vomitus was so small in comparison with that of urine that the chloride actually lost in the urine was usually far in excess of that in the vomitus. Further, they found that vomiting in nephritis does not eliminate chloride alone, but also a considerable amount of base. This they offered as partial explanation for lack of bicarbonate excess even with the most persistent emesis. The absence of alkalosis was attributed in part, furthermore, to the tendency to lose base in the urine in combination with acids which would ordinarily be neutralized by ammonia, since it had been shown by Van Slyke, Linder, Hiller, Leiter and McIntosh (22) that there is a decreased ability in nephritis to form ammonia.

It is of interest then to consider Cases 1 and 2 in detail, since they were the only ones to show vomiting. At no time during the period of observation was alkali administered. Case 1 presented persistent vomiting from February 7 to March 1, during which time, over a period of several days at a time, very little food could be retained. Oral administration of $\mathrm{NaCl}, \mathrm{NH}_{4} \mathrm{Cl}$ and dilute $\mathrm{HCl}$ was attempted from February 23 to March 9. Very little was retained as a result of the vomiting. Case 2 showed intermittent vomiting spells from the first observation until termination. Both of these cases showed a progressive fall in chloride and total base concentrations. The decrease in total base was not as great as the fall in chloride and the difference was more than made up by an increase in bicarbonate. The total measured acid concentration, however, showed a progressive decrease. A high pH was observed in both instances. Case 1 showed 
a condition of uncompensated alkalosis over a period of twenty-two days just preceding death. Case 2 attained a maximum plasma bicarbonate concentration of $35 \mathrm{~m}$.Eq. No analyses were made of the vomitus so that the amount of acid and base lost by this route is not known. It may be that in these cases with little nitrogen retention there is considerably more free $\mathrm{HCl}$ lost in the vomitus than in those described by Peters, Wakeman and Lee (21).

Hartman, Smyth and Moser (20) found that $\mathrm{Cl}$ seldom appeared in the urine or only in very small amounts when the serum chloride was below 90 milliequivalents. Peters, Wakeman and Lee (21) have shown that in some cases of nephritis there is a tendency for both base and chloride to be excreted in the urine when the serum chloride has fallen below the level which in normal individuals determines achloruria. In Case 1 (see Table II) the plasma chloride concentration was definitely below $90 \mathrm{~m}$.Eq., yet chloride was appearing in the urine. On the other hand there was apparently a conservation of base in that even though the bicarbonate concentration of the plasma was definitely above normal, the urine showed an acid reaction. In the other cases studied, the urine showed an acid reaction with the exception of Case 3. Case 6 had an extremely acid reaction while Case 4 had a urine acid to pH 6.0 in spite of the $31 \mathrm{~m}$.Eq. plasma bicarbonate concentration. It is of interest in this connection that Kast, Myers and Schmitz (14) pointed out that in certain cases alkalosis is readily produced by bicarbonate administration for the reason that the kidneys do not readily eliminate alkali. In two of their cases the urine remained strongly acid ( $\mathrm{pH} 5.2$ and 5.12) despite an alkalosis.

The changes in acid-base balance appear in general to be such that a lowered plasma chloride accompanies the elevated bicarbonate. The elevated bicarbonate may be present in spite of a lowered total base concentration. In Cases $1,2,4,5$ and 10, the elevated bicarbonate was accompanied by a total base concentration below 150 m.Eq. and a chloride concentration at or below $100 \mathrm{~m}$.Eq. It might be inferred that in these cases there were complications of heart failure with high bicarbonate as a result of anoxic anoxemia as reported by Peters, Bulger, and Eisenman (23). Cases 1 through 9 were under careful observation since they were on the service of one of us (C. T. W.) 
TABLE II

Urine changes in cases of persistent hypertension

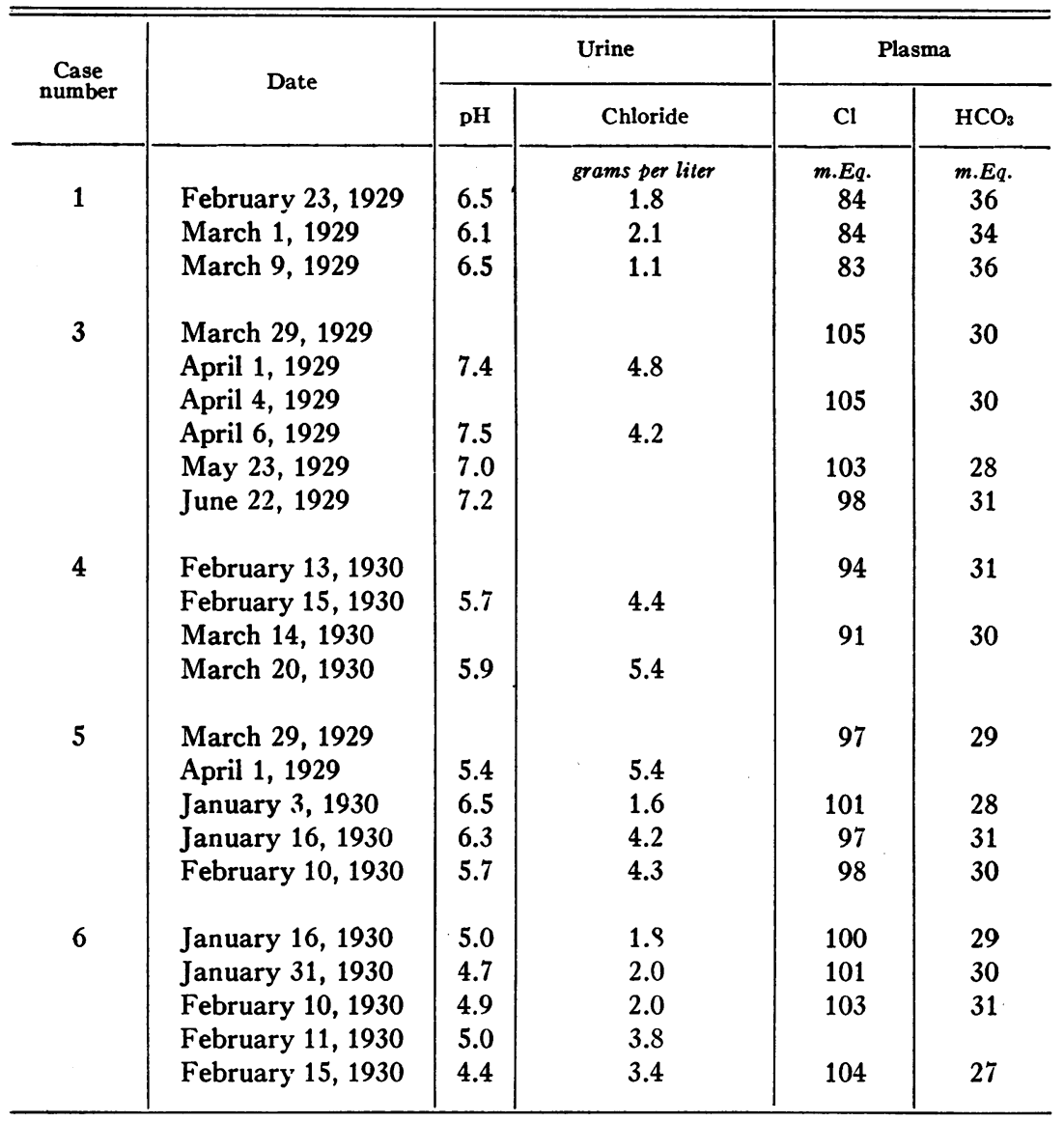

in the Medical Wards of St. Luke's Hospital. Cardiac insufficiency was in evidence in Cases 3, 4, 5 and 6 at some time during the period of observation. It should be pointed out, however, that no cardiac insufficiency was present in Cases 1, 2 and 7 where the highest plasma bicarbonate concentrations were observed. Further, in Case 3, during the early period of observation when an alkalosis was manifested, cardiac insufficiency was not a pronounced factor. During the later period of observation a very considerable degree of edema developed and myocardial insufficiency was in evidence, but at this time the 
bicarbonate concentration had fallen to such a degree that an acidosis existed.

Salvesen (12) found that an acidosis is of frequent occurrence in diseases of renal origin, whereas an alkalosis is very seldom if ever met with. However, he pointed out that a change in the $\mathrm{pH}$ to the alkaline side, due probably to a low $\mathrm{CO}_{2}$ pressure, may be seen more frequently. Unusual clinical interest is attached to Cases 1, 2, 4 and 12 of this study. The pictures they presented would have been regarded as typical examples of acidosis had not the determinations of the plasma $\mathrm{CO}_{2}$ content revealed the presence of an alkalosis. Attention has frequently been called to the marked similarity of the clinical pictures of these two disturbances of the acid-base balance and the frequent necessity for chemical blood studies for their differentiation. Therapeutic efforts to control the alkalosis associated with hypertension have been of little, if any, value in averting the fatal issue. Where chloride depletion is the result of vomiting the administration of chloride would seem to be indicated. Oral administration of chloride was attempted with Case 1. Little of value was accomplished due to the interference from the vomiting. Intravenous administration of chloride would probably have given some relief.

\section{SUMMARY}

1. A study of the acid-base equilibrium has been made in twelve cases showing persistent hypertension with only slight nitrogen retention.

2. A plasma bicarbonate content above $31 \mathrm{~m}$.Eq. was observed in six cases, while an elevation of plasma $\mathrm{pH}$ to above 7.48 was found in all but one case.

3. Two cases presented severe vomiting which was accompanied by a loss of chloride and total base from the blood, and an elevation of bicarbonate.

4. Chloride and total base concentrations were very irregular. The chloride concentration in the majority of cases was below 100 m.Eq. In several cases a high bicarbonate was in evidence even in the presence of a low total base concentration.

5. It is logical to expect that if vomiting occurs in cases having a tendency to an elevated bicarbonate and a lowered chloride concentration, a condition of alkalosis will result. 


\section{BIBLIOGRAPHY}

1. Whitney, J. L., Arch. Int. Med., 1917, xx, 931. Studies on Acidosis: The Immediate Cause of Death, and Remarks on the Acidosis of Nephritis.

2. Chace, A. F. and Myers, V. C., J. Am. Med. Assoc., 1920, lxxiv, 641. Acidosis in Nephritis.

3. Marriott, W. M. and Howland, J., Arch. Int. Med., 1916, xviii, 708. Phosphate Retention as a Factor in the Production of Acidosis in Nephritis.

4. Greenwald, I., J. Biol. Chem., 1915, xxi, 29. The Estimation of Lipoid and Acid-Soluble Phosphorus in Small Amounts of Serum.

5. Denis, W. and Minot, A. S., Arch. Int. Med., 1920, xxvi, 99. A Study of Phosphate Retention from the Standpoint of Blood Analysis.

6. Salvesen, H. A. and Linder, G. C., J. Biol. Chem., 1923, lviii, 617. Observations on the Inorganic Bases and Phosphates in Relation to the Protein of Blood and Other Body Fluids in Bright's Disease and in Heart Failure.

7. Schmitz, H. W., Rohdenburg, E. L. and Myers, V. C., Arch. Int. Med., 1926, xxxvii, 233. The Inorganic Phosphorus and Calcium of the Blood in Nephritis.

8. De Wesselow, O. L. V., Quart. J. Med., 1923, xvi, 341. On the Phosphorus and Calcium of the Blood in Renal Disease.

9. Denis, W. and Hobson, S., J. Biol. Chem., 1923, lv, 183. A Study of the Inorganic Constituents of the Blood Serum in Nephritis.

10. Loeb, R. F. and Benedict, E. M., J. Clin. Invest., 1927, iv, 33 . Inorganic Sulfates in Human Blood.

11. Wakefield, E. G., Arch. Int. Med., 1929, xliv, 244. Inorganic Serum Sulfates in Renal Insufficiency.

12. Salvesen, H. A., Acta Med. Scandinav., 1928, lxix, 126. Variations in Serum Electrolytes in Diseases of Renal Origin with Special Reference to the Cause of Renal Acidosis.

13. Peters, J. P., Wakeman, A. M., Eisenman, A. J. and Lee, C., J. Clin. Invest., 1929, vi, 517. Total Acid-Base Equilibrium of Plasma in Health and Disease. X. The Acidosis of Nephritis.

14. Kast, L., Myers, V. C. and Schmitz, H. W., J. Am. Med. Assoc., 1924, lxxxii, 1858. Clinical Conditions of Alkalosis.

15. Myers, V. C. and Muntwyler, E., J. Biol. Chem., 1928, Ixxviii, 243. The Colorimetric Estimation of the Hydrogen Ion Concentration of Blood.

16. Van Slyke, D. D. and Neill, J. M., J. Biol. Chem., 1924, lxi, 523. The Determination of Gases in Blood and Other Solutions by Vacuum Extraction and Manometric Measurement. I.

17. Van Slyke, D. D., J. Biol. Chem., 1923, lviii, 523. The Determination of Chlorides in Blood and Tissues. 
18. Wilson, D. W. and Ball, E. G., J. Biol. Chem., 1928, lxxix, 221. A Study of the Estimation of Chloride in Blood and Serum.

19. Stadie, W. C. and Ross, E. C., J. Biol. Chem., 1925, 1xv, 735. A Micro Method for the Determination of Base in Blood and Serum and Other Biological Materials.

20. Hartman, A. F:, Smyth, F. S. with Moser, A. E., Am. J. Dis. Child., 1926, xxxii, 1. Chemical Changes in the Body Occurring as the Result of Vomiting.

21. Peters, J. P., Wakeman, A. M. and Lee, C., J. Clin. Invest., 1929, vi, 551. Total Acid-Base Equilibrium of Plasma in Health and Disease. XI. Hypochloremia and Total Salt Deficiency in Nephritis.

22. Van Slyke, D. D., Linder, G. C., Hiller, A., Leiter, L. and McIntosh, J. F., J. Clin. Invest., 1926, ii, 255. The Excretion of Ammonia and Titratable Acid in Nephritis.

23. Peters, J. P., Bulger, H. A. and Eisenman, A. J., J. Clin. Invest., 1926, iii, 511. Total Acid-Base Equilibrium of Plasma in Health and Disease. IX. High Serum Bicarbonate in Heart Failure. Asphyctic Anoxemia.

\section{CASE HISTORIES}

Case 1. 70812. T. W., female, aged 38, housewife, was observed over approximately two and one-half years. Her chief complaints were headaches, accompanied by nausea and vomiting, throbbing in the head, numbness and tingling in extremities, progressive weight loss and nocturia. During the latter period of her illness vision was seriously impaired.

The salient physical and laboratory findings were slight cardiac enlargement, systolic blood pressure which varied from 180 to 260 , and diastolic pressure from 130 to 160 ; fundi of both eyes showed arteriosclerotic changes; the uterus was about the size of a grapefruit, firm and apparently fibroid in nature; urine showed a trace of protein during the last year of observation with occasional hyaline and granular casts; serological studies of both blood and spinal fluid were negative; complete gastro-intestinal $x$-ray findings were negative.

During the latter part of this patient's illness her most distressing problems were headache and vomiting, from which it was almost impossible to afford any effective relief; consequently weight loss was very marked. During the last week of life typical carpopedal spasm was observed. A period of stupor of about two days' duration preceded death.

Clinical Diagnosis: Malignant hypertension, cardiac hypertrophy.

Case 2. 69473. J. A. W., male, aged 24, bookkeeper, was first seen July 17,1928 , at which time his chief complaints were headaches, periodic in nature, occasionally accompanied by nausea and vomiting; slight swelling of both ankles; spots before the eyes; and nocturia two or three times a night. 
History revealed a severe scarlet fever four years previous, several attacks of acute tonsillitis, appendectomy in 1918 and tonsillectomy in 1922.

A period of hospitalization at this time resulted in the following findings: albuminuric retinitis, slight cardiac enlargement, slight edema of both ankles; systolic blood pressure varied between 232 and 190 and diastolic varied from 160 to 120 . Modified Mosenthal test showed a practically fixed specific gravity at a low level. Variations in day specimens were between 1.010 and 1.014. The night quantity from 8 P.M. to 8 A.M. showed a volume of $995 \mathrm{cc}$. and a specific gravity of 1.010 . Urine analysis showed a trace of protein and numerous hyaline and finely granular casts, a few erythrocytes and a few leucocytes.

On August 16, 1928, approximately a month after first examination, after a very severe headache, patient was taken with convulsions and for three days remained in a stuporous state. Blood pressure was 200 systolic, 120 diastolic at this time. With usual therapeutic measures, including venisection, he gradually improved and was able to leave the hospital in three weeks. During this time the highest blood urea nitrogen observed was 28.5 $\mathrm{mgm}$. and creatinine, $4.1 \mathrm{mgm}$. Phenolsulphonphthalein excretion was 32 per cent in two hours.

The final acid-base study, made October 24, 1928, was just two days before death. Patient became progressively weaker and died October 26, 1928 , in coma.

Clinical Diagnosis: Chronic glomerular nephritis, cardiac hypertrophy, slight.

Case 3. 73623. J. H., female, aged 58, housewife, complained of an illness of five years' duration, characterized by throbbing in the head, shortness of breath, nocturia, headaches and progressive weight loss. Periods of dyspnea at night of considerable severity would occur, accompanied by pain in the precordial region and in both shoulders and back. Blood pressure varied between 220 and 166 systolic and between 120 and 140 diastolic. This patient was under observation for about two years. During the early part of this period there was slight swelling of the ankles on numerous occasions. About one month before death a generalized edema developed which continued to grow worse until death. The urine constantly showed a trace to a moderate amount of protein with numerous hyaline and granular casts and was always of a low specific gravity, between 1.008 and 1.012 on numerous examinations. There was a progressive anemia as evidenced by oxygen capacity studies -of the blood, which varied from 15 volumes per cent at the beginning of the study down to 9.4 volumes per cent at the time of the last analysis. Electrocardiographic study of the heart revealed a partial bundle branch block. Eye ground examination showed a marked degree of arteriosclerotic change involving both fundi. A period of coma of five days' duration preceded death.

Clinical Diagnosis: Hypertension with evidence of kidney insufficiency, 
generalized arteriosclerosis, partial bundle branch heart block, cardiac hypertrophy.

Case 4. 82380. M. H., female, white, aged 46, housewife. Present illness was of more than five years' duration, during which main symptoms have been severe and frequent headaches, frequency of urination day and night, and weight loss. Just before entering hospital she lapsed into a state of coma.

Physical examination revealed a well developed but poorly nourished woman in a state of coma, exhibiting Cheyne Stokes respiration. Positive findings were cardiac enlargement to left anterior axillary line, systolic murmur audible over entire precordium, pulse rate 100 and regular, liver palpable three fingers' breadth below costal margin and slight edema of both ankles. Palpable arteries were sclerotic. Blood pressure ranged between 270 and 228 systolic and 160 to 150 diastolic. Eye grounds showed marked sclerosis of retinal vessels. Blood nonprotein nitrogen was 30.4 and 31.8. Urine showed a moderate amount of protein, a few leucocytes and occasional hyaline and granular casts. The last observation reported in Table I was just two weeks before death occurred. When the blood samples were taken, signs of cardiac failure were not present to an appreciable degree.

Final Pathological Diagnosis: Arteriolosclerosis of spleen, pancreas, adrenals and kidneys; marked arteriolosclerotic atrophy of kidneys, with multiple small anemic and hemorrhagic infarctions; hypertrophy and dilatation of heart, very marked; multiple small anemic infarctions of myocardium; multiple mural thrombi of both ventricles and right auricle; multiple hemorrhagic infarctions of both lungs; acute interstitial pancreatitis, with discrete areas of necrosis, slight; chronic passive congestion of liver, spleen, and small intestine; senile emphysema of lungs, very marked; intense congestion of trigone and first portion of urethra, with submucous hemorrhages; thrombosis of ovarian veins; emaciation; senile atrophy of ovaries; anthracosis of lungs, slight; moderate intimal fatty infiltration of the aorta and coronary arteries; mild healed aortic endocarditis; diverticula of bladder, two in number: a small cavernous angioma of liver; slight melanosis coli.

Case 5. 74650. A. K., female, white, aged 77, housewife. Main complaints were headaches, shortness of breath, dizziness, frequency of urination day and night, and pain in substernal region. Physical examination revealed an undernourished elderly woman, many carious teeth, moderate cardiac enlargement, marked sclerosis of all accessible arteries, and a blood pressure which varied between 225 and 170 systolic and 100 to 130 diastolic. Urine analysis revealed a trace of protein, and on a few occasions a positive sugar. Blood urea nitrogen was never observed above $16.1 \mathrm{mgm}$. per $100 \mathrm{cc}$. Blood sugar values were moderately elevated during latter part of illness, the highest value observed being $273 \mathrm{mgm}$. Electro- 
cardiographic study showed evidence of myocardial involvement and left ventricular preponderance. Before death a marked degree of edema developed.

Final Pathological Diagnosis: Bronchopneumonia, slight; edema and congestion of lungs; diffuse hemorrhagic infarctions of lower lobe of right lung, with embolism of the corresponding artery; slight hyperplasia of splenic pulp; hydrothorax, bilateral; hypertrophy and dilatation of left ventricle; moderate arteriosclerosis of coronary arteries; recent anemic infarctions of papillary muscle of left ventricle; severe arteriosclerosis of aorta, especially at the lumbar portion; marked arteriosclerosis of aortic branches, especially of the iliacs; angiosclerosis of kidneys, slight; angiosclerosis of pancreas, marked; chronic interstitial pancreatitis, moderate, with old focal fat necrosis; edema of right hand, right leg, and external genitalia; anemia; emaciation; old firm adhesion of omentum to left Fallopian tube; old adhesions about gallbladder; adenoma of right adrenal; senile emphysema of lungs; senile atrophy of liver, spleen, adrenals, internal genitalia, and breast. Nodular hyperplasia of splenic pulp and marked angiosclerosis of spleen.

Case 6. 80440 . S. O., female, aged 66, white, housewife. Present illness of seven years' duration, the main symptoms being headaches, dyspnea, palpitation, dizziness and nocturia. Physical examination showed a moderately obese female, with moderate cardiac enlargement, and no demonstrable edema. Blood pressure varied during 40 days' observation from 220 to 190 systolic and from 128 to 104 diastolic. Eye grounds showed arteriosclerotic retinitis. Leucocytes, 8800; hemoglobin, 85 per cent; phthalein test, 10 per cent the first hour and 25 per cent the second hour. Variations in specific gravity of 2 hour day specimens of urine were from 1.004 to 1.008 . Volume of urine, 8:00 P.M. to 8:00 A.M., was $1005 \mathrm{cc}$. with a specific gravity of 1.018. Blood chemical studies failed to show any degree of nitrogen retention. Subject is still living.

Clinical Diagnosis: Hypertension with evidence of kidney insufficiency, cardiac hypertrophy.

Case 7. 76444. L. D., female, aged 56, white, housewife. Present illness was of one year's duration; onset occurred with numbness and loss of function of left side of body, which recovered with bed rest. A similar accident occurred one year later. Headache, dizziness and nocturia were constantly experienced throughout illness. Blood pressure was systolic 198, diastolic 106. Urinalysis showed no protein, but an occasional hyaline cast. Blood count: red blood cells, 4,270,000; leucocytes, 7400; hemoglobin, 78 per cent. Blood chemistry: blood sugar, $91 \mathrm{mgm}$., and urea nitrogen, 11.9 mgm. Patient is still living.

Clinical Diagnosis: Cerebral hemorrhage, generalized arteriosclerosis, hypertension.

Case 8. E. B., female, aged 53, white, housewife. Illness was of five 
years' duration characterized by headaches, constipation, dizziness, tingling of fingers and toes, nocturia, and for the last year, failing vision.

Chief physical findings were obesity, edema beneath both eyes, moderate cardiac enlargement, blood pressure, systolic 250, diastolic 140 . Urine showed trace of protein, hyaline and granular casts. Patient refused to enter hospital for more detailed study; consequently complete findings are not available.

Clinical Diagnosis: Hypertension, malignant, cardiac hypertrophy.

Case 9. K. 1225. T. H., female, aged 60, white, housewife. Present illness was of four years' duration, during which time three mild apoplectic strokes occurred. Numbness and tingling of fingers and toes, nocturia and occasional headaches with vertigo have been experienced.

Physical examination revealed a slightly undernourished white female. There was slight left facial asymmetry with paralysis of whole left side of body. Heart was moderately enlarged to the left with accentuated aortic second sound. Accessible vessels were markedly sclerotic. Eye grounds examination showed arteriosclerotic retinitis. Blood pressure varied from 230 to 180 systolic and 130 to 95 diastolic. Red blood cells, 4,300,000: leucocytes, 8200; hemoglobin, 80 per cent. Urine showed a trace of protein, hyaline and granular casts. Blood Wassermann was negative. Spinal fluid cell count, 4 per c.mm.; globulin, negative. Blood urea nitrogen, 12.4 and $13.4 \mathrm{mgm}$. per $100 \mathrm{cc}$. on two examinations.

Clinical Diagnosis: Arteriosclerosis, general, hypertension, cerebral hemorrhage.

Case 10. 82588. C. D., female, aged 61, white, housewife. Present illness was of about ten years' duration, characterized by headaches, dizziness and nocturia. Bed rest on a number of occasions for varying periods resulted in subjective improvement. Salient features of physical examination were obesity, slight cardiac enlargement, obese and pendulous abdomen, no edema, moderate cardiac enlargement. Blood pressure varied from 186 to 256 systolic and 110 to 160 diastolic. Red blood cells, 4,540,000; leucocytes, 8100; hemoglobin, 90 per cent Mosenthal test showed a fixation of specific gravity at a low level, the eatest variation being between 1.005 and 1.012. Night volume was 11 .5 cc. with specific gravity 1.007 . Eye grounds showed arteriosclerotic $ن$ inits. Urinalysis revealed protein in moderate amount, hyaline and graı ularcasts.

Clinical Diagnosis: Malignant hypertension with evidence of kidney insufficiency, cardiac hypertrophy.

Case 11. 77120. J. S., male, aged 63, white. Onset of present illness was marked by a paralytic stroke involving left side of body, one year ago, with recovery. There had been swelling of feet and ankles and dyspnea for one year. A second stroke involving left side occurred four months ago. A third stroke affecting the left side of the body and the speech center led to present hospitalization. 
Physical examination showed: fixation of right pupil, left side of mouth droops, cardiac enlargement, liver not palpable, pitting edema of both legs, knee jerks hyperactive. Blood pressure: systolic 210, diastolic 130 . Leucocytes, 5850; hemoglobin, 70 per cent. Urine: acid, trace of protein, no casts. Wassermann, negative. Blood urea nitrogen, $20 \mathrm{mgm}$. per $100 \mathrm{cc}$; blood glucose, $100 \mathrm{mgm}$. per $100 \mathrm{cc}$.

Clinical Diagnosis: Diffuse hyperplastic arteriosclerosis, cardiac hypertrophy, right cerebral hemorrhage.

Case 12. 82884. M. C., female, aged 48, white, housewife. Complaint was of ten years' duration, characterized by headaches, dizziness and nocturia. Past history included numerous infected teeth and acute appendicitis, which was followed by fecal fistula which later healed. Physical examination showed marked obesity, no demonstrable cardiac enlargement, soft systolic murmur over aortic area. Blood pressure varied during three day period of observation from 230 to 186 systolic and from 130 to 90 diastolic. Eye grounds showed sclerosis of retinal vessels.

Blood urea nitrogen varied from $25.7 \mathrm{mgm}$. on admission to 67.5 before death. Blood sugar varied between 113 and $170 \mathrm{mgm}$., uric acid from 4.4 to 7.4 , nonprotein nitrogen from 50 to 132 , and creatinine from 6.2 to $11.3 \mathrm{mgm}$. Red blood cells, 4,800,000; leucocytes, 8000; hemoglobin, 90 per cent. Urinalysis showed trace of protein and a few hyaline casts. Death occurred in a state of uremia with a complicating hypostatic pneumonia.

Clinical Diagnosis: Hypertension with evidence of kidney insufficiency, uremia and hypostatic pneumonia. 